Article

\title{
Additive Manufacturing of Geopolymers Modified with Microalgal Biomass Biofiller from Wastewater Treatment Plants
}

\author{
Emanuele Agnoli ${ }^{1, * \mathbb{C}}$, Riccardo Ciapponi ${ }^{2}$, Marinella Levi ${ }^{1}$ and Stefano Turri ${ }^{1,2}$ \\ 1 Department of Chemistry, Materials and Chemical Engineering “Giulio Natta”, Politecnico di Milano, Piazza \\ Leonardo da Vinci 32, 20133 Milano, Italy; marinella.levi@polimi.it (M.L.); stefano.turri@polimi.it (S.T.) \\ 2 INSTM-National Interuniversity Consortium of Materials Science and Technology, Via G. Giusti 9, \\ 50121 Firenze, Italy; riccardo.ciapponi@polimi.it \\ * Correspondence: emanuele.agnoli@mail.polimi.it; Tel.: +39-0223994703
}

Received: 26 February 2019; Accepted: 25 March 2019; Published: 27 March 2019

\begin{abstract}
This paper deals with the additive manufacturing of metakaolin-based geopolymers and with the use of microalgal biomass from wastewater treatment plants as biofiller in this kind of cementitious material. The study was developed following the evolution stages of the material, which was prepared and printed as a soft paste and then hardened thanks to an inorganic polymerization reaction (geopolymerization). Thus, the characterization techniques adopted encompassed rheometry, mechanical tests performed on the hardened material, scanning electron microscopy (SEM), energy-dispersive X-ray spectroscopy (EDS) and mercury intrusion porosimetry (MIP). Microalgal biomass addition, evaluated in this study at 1, 3 and 5 php with respect to the powder weight, affected both the properties of the fresh and of the hardened material. Regarding the former aspect, biomass reduced the yield stress of the pastes, improving the ease of the extrusion process, but potentially worsening the ability to build structures in height. When hardened, geopolymers containing microalgae showed mechanical properties comparable to the unfilled material and a microstructure characterized by smaller pores. Finally, a printing test was successfully performed with a larger printer to assess the feasibility of producing large-scale structures. Taking into account these results, this study demonstrates the possibility of using microalgal biomass as biofiller in geopolymers for additive manufacturing.
\end{abstract}

Keywords: additive manufacturing; 3D printing; liquid deposition modeling; geopolymers; metakaolin; biofillers; end-of-life materials; microalgae; SaltGae

\section{Introduction}

The possibility to produce objects directly from a 3D digital model has made additive manufacturing (AM), also popularly known as 3D printing, attractive for a wide range of applications in many different sectors. Traditionally known as a technology suitable for making prototypes and mockups rapidly, recently AM has become interesting to obtain easily customizable, functional final product [1-4].

One of the most promising application of AM is in the construction field, which is already moving toward a digitalization of processes at the design phase, with the use of building information models (BIM), and is seeking for automation also in the construction phase [5]. AM can improve this sector, by introducing a new freedom in design, and by reducing manpower, construction time, material consumption and, consequently, costs [6,7].

3D printing of cementitious materials has been studied and, in some cases, scaled-up to obtain real buildings. AM technologies in this field can be divided in two broad categories: powder-based and 
extrusion-based. In techniques following the former approach, a liquid binder is jetted on a powder bed to make particles stick together, building the object layer-by-layer; high resolution and mechanical properties can be achieved, but the printing speed is low, and the dimension of printed object is limited by that of the frame containing the powder bed $[8,9]$. Conversely, in extrusion-based processes the cementitious material is extruded in a fresh state to build freeform structures layer-by-layer; although resolution is lower with respect to powder-based techniques, printing speed is much higher and in principle, there are no limitations on the dimensions of the structure $[10,11]$. Because of these aspects, in this paper an extrusion-based process, called liquid deposition modeling (LDM) [12,13], is studied.

A cementitious paste for LDM should comply mainly with two requirements: printability and buildability. From the printability point of view, the paste must be extruded easily and in a reliable way, forming continuous filaments, avoiding plugging at the nozzle and too high of a pressure build-up that may significantly affect the printing quality. Buildability, on the other hand, can be expressed as the ability of the material to sustain the loads due to the subsequent layers deposited. In addition, open time, that is the period of time in which a mortar is workable, must be taken into account to avoid the hardening of the cementitious material in the printing system [14,15].

Along with the automation of the building technologies, advancement in construction industry must pass through the evolution of building materials. Nowadays, ordinary Portland cement (OPC)-based concrete is the most widely used construction material. Current average consumption of concrete is about $1 \mathrm{t} /$ year per every living human being, second only to water consumption. Due to its large demand, even small reductions of greenhouse gas emissions per ton of manufactured concrete can make a significant global impact. Since the production of 1 ton of OPC implies the emission of about 0.5 tons of carbon dioxide and an intensive use of energy, the easiest solution to reduce the environmental impact of construction industry is shifting to alternative cementitious binders $[16,17]$. In recent years geopolymers, also called alkali-activated cements (AAC), are emerging as promising cementitious materials to provide an environmentally friendly alternative to OPC, since the production of raw materials is less polluting and energy-intensive than OPC [16,18-22]. In particular, from the comparison of the life cycle assessment (LCA) studies present in literature, Habert and Oullet-Plamondon concluded that AAC can reduce global warming potential (GWP), i.e., the environmental impact category related to greenhouse gases emissions, by a factor of 4 compared to OPC [23]. Regarding other environmental impact categories, related to nitrogen cycle and biodiversity loss, benefits are less clear. Specifically, further research developments are needed to improve the sustainability of the alkaline activation process, using wastes instead of pure materials to obtain the precursors for alkaline solutions $[18,23]$.

Typically, geopolymers are obtained by mixing an aluminosilicate source (e.g., metakaolin, fly-ash or granulated blast furnace slag) with an alkaline solution (called alkaline activator); alkaline environment is needed to dissolve aluminosilicates and to trigger a polycondensation reaction (geopolymerization). Passing through various steps, particles coagulate and condense to form a polycrystalline or amorphous solid material [24-29].

To reduce the environmental impact of concrete further, waste materials (inorganic and organic) can be adopted in cement industry as fillers and even property modifiers [19,30,31]. This paper deals with microalgal biofillers, which are wastes of innovative wastewater treatment plants based on filtration by microalgae. These plants take advantage of the naturally occurring phenomenon of eutrophication: in presence of water containing high concentrations of nutrients, the growth of algae is highly promoted. In natural environments, eutrophication can cause the death of other organisms due to the reduction of the oxygen level, but this phenomenon can be positively used in wastewater treatments to remove nutrients and heavy metals from wastewaters before their discharge [32-34].

This work is part of the project SaltGae, funded by EU in the framework of Horizon 2020 research and innovation program. The aim of the project is to implement and demonstrate at large scale the long-term technological and economic feasibility of an innovative, sustainable and efficient solution for the treatment of high salinity wastewater based on the use of microalgae. In addition, 
in order to minimize the economic and environmental impact of the treatment, SaltGae includes in its workplan the valorization of end-of-life algal biomass into different by-products for high value-added applications [35].

Therefore, the aim of this work is related to the byproducts' valorization aspect. In particular, geopolymers for LDM technology were studied, focusing on the effect of microalgal biomass addition on the properties of fresh and hardened material.

\section{Materials and Methods}

\subsection{Raw Materials}

To produce geopolymer formulations for LDM, metakaolin, an alkaline activator composed of sodium silicate and sodium hydroxide solutions, bentonite and distilled water were used. Two microalgal biomass species (Spirulina platensis and Tetraselmis suecica) and lignin were added in different amounts to the mixtures. Lignin was used as a reference biomass, available as waste from the paper industry, to be compared with microalgal species.

The metakaolin used in this work, with the commercial name Mefisto L05, was provided by České Lupkové Závody (Pecínov, Czech Republic). The specific surface area of the powder was $12.69 \mathrm{~m}^{2} / \mathrm{g}$, LOI $2.20 \%, d_{50} 3 \mu \mathrm{m}$ and $d_{90} 10 \mu \mathrm{m}$. The chemical composition guaranteed by the supplier is shown in Table 1.

Table 1. Chemical composition of Metakaolin Mefisto L05.

\begin{tabular}{ccccccc}
\hline $\mathrm{Al}_{2} \mathrm{O}_{3}(w t \%)$ & $\mathrm{SiO}_{2}(w t \%)$ & $\mathrm{K}_{\mathbf{2}} \mathbf{O}(w \mathrm{w} \%)$ & $\mathrm{Fe}_{2} \mathrm{O}_{3}(w \mathrm{t} \%)$ & $\mathrm{TiO}_{2}(w t \%)$ & $\mathbf{M g O}(w t \%)$ & $\mathrm{CaO}(w t \%)$ \\
\hline 41.1 & 54.1 & 0.8 & 1.1 & 1.8 & 0.18 & 0.13 \\
\hline
\end{tabular}

A commercial solution-based alkaline activator, with a formulation based on sodium silicate and sodium hydroxide, was purchased by České Lupkové Závody (Pecínov, Czech Republic), in bundle with the metakaolin powder. Thermogravimetric analysis performed on the activator solution showed that the water content is $62 \mathrm{wt} \%$.

Bentonite, which is an absorbent aluminum phyllosilicate clay consisting mostly of montmorillonite, was used in geopolymer pastes as a rheology modifier, to increase plasticity and to obtain a proper viscosity. A commercial bentonite, "Mapeproof Seal", was purchased by Mapei (Milano, Italy).

Microalgal biomasses, Spirulina platensis and Tetraselmis suecica, were kindly provided by the SaltGae partner Archimede Ricerche (Camporosso, Italy) as freeze-dried powders. Chemical analyses on Spirulina and Tetraselmis, performed by the partner Extractis (Dury, France), are reported in Table 2.

Table 2. Chemical composition of microalgal biomasses used in this work (Spirulina platensis and Tetraselmis suecica).

\begin{tabular}{ccc}
\hline Component & Spirulina platensis & Tetraselmis suecica \\
\hline Dry Matter $^{2}$ & 97.49 & 95.16 \\
Ash $^{2}$ & 9.12 & 17.05 \\
Proteins $^{2}$ & 67.78 & 37.89 \\
Total sugars $^{2}$ & 9.31 & 14.49 \\
Total free sugars $^{2}$ & 2.79 & 4.19 \\
Lipids $^{2}$ & 6.26 & 12.82 \\
Other $^{2}$ & 4.74 & 13.56
\end{tabular}
${ }^{1}$ Dry matter wt \% is computed over the total weight of the sample analyzed. ${ }^{2}$ The component wt $\%$ is computed
over the weight of the dry matter.

The softwood Kraft lignin used in this work, "Indulin AT", was provided by MeadWestvaco (Richmond, VA, USA) as a powder. 


\subsection{Formulations}

Geopolymer mixtures for LDM were optimized in order to comply with the requirements of printability and buildability. These aspects strongly depend on the printing setup. Therefore, passing from an extrusion system to another (e.g., from syringe-based to screw-based extruders) or changing the scale of printing may require the adjustment of mixture proportions.

Table 3 reports the mixture compositions analyzed in this work. All formulations were based on the mixture of the metakaolin and the alkaline activator in a fixed mass ratio of $5 / 4$. Bentonite and water were added to adjust rheological behavior. To investigate the effect of biomass addition on geopolymer properties, three different biomass contents were selected: 1, 3 and 5 per hundred parts (php) with respect to the powder weight, i.e., metakaolin and bentonite. These numbers are reported in the formulation ID, next to a letter indicating the biomass type ("S" for Spirulina, " $\mathrm{T}$ " for Tetraselmis, "L" for lignin). Higher quantities of biomass led to too stiff and dry mixtures, difficult or impossible to print. Formulations containing biomass were compared to the unmodified geopolymer mixture (G-0). The formulation U-S5, containing Spirulina by $5 \mathrm{php}$, was tuned for the scale-up printing (refer to Section 2.3).

Table 3. Mixture proportions of cementitious geopolymer pastes for LDM applications.

\begin{tabular}{|c|c|c|c|c|c|c|c|}
\hline $\begin{array}{l}\text { Formulation } \\
\text { ID }\end{array}$ & $\begin{array}{l}\text { Metakaolin } \\
\quad(w t \%)\end{array}$ & $\begin{array}{c}\text { Alkaline } \\
\text { Activator } \\
\text { (wt \%) }\end{array}$ & $\begin{array}{c}\text { Bentonite } \\
\text { (wt \%) }\end{array}$ & $\begin{array}{l}\text { Water } \\
\text { (wt \%) }\end{array}$ & $\begin{array}{c}\text { Spirulina } \\
\text { platensis } \\
\text { (wt \%) }\end{array}$ & $\begin{array}{c}\text { Tetraselmis } \\
\text { suecica } \\
\text { (wt \%) }\end{array}$ & $\begin{array}{l}\text { Lignin } \\
\text { (wt \%) }\end{array}$ \\
\hline G-0 & 37.6 & 30.0 & 22.6 & 9.8 & - & - & - \\
\hline G-S1 & 37.0 & 29.5 & 22.2 & 10.6 & 0.6 & - & - \\
\hline G-S3 & 36.2 & 28.9 & 21.8 & 11.4 & 1.7 & - & - \\
\hline G-S5 & 35.5 & 28.3 & 21.3 & 12.1 & 2.8 & - & - \\
\hline G-T1 & 37.0 & 29.5 & 22.2 & 10.6 & - & 0.6 & - \\
\hline G-T3 & 36.2 & 28.9 & 21.8 & 11.4 & - & 1.7 & - \\
\hline G-T5 & 35.5 & 28.3 & 21.3 & 12.1 & - & 2.8 & - \\
\hline G-L1 & 37.0 & 29.5 & 22.2 & 10.6 & - & - & 0.6 \\
\hline G-L3 & 36.2 & 28.9 & 21.8 & 11.4 & - & - & 1.7 \\
\hline G-L5 & 35.5 & 28.3 & 21.3 & 12.1 & - & - & 2.8 \\
\hline U-S5 & 47.7 & 38.0 & 10.4 & 0.7 & 3.1 & - & - \\
\hline
\end{tabular}

The powders (i.e., metakaolin, bentonite and biomass) were weighed in a plastic beaker and manually mixed with a spatula for about $1 \mathrm{~min}$. Then, the liquids were weighed and added in the same beaker. Liquids and powders were incorporated by mixing them manually with a spatula for about $5 \mathrm{~min}$, until a uniform paste was obtained. An electric mortar mixer was used for the larger scale printing test.

\subsection{Printing Setups and Preparation of the Specimens}

A desktop fused deposition modelling (FDM) 3D printer, 3DRag, produced by Futura Elettronica (Gallarate, Italy), was modified for LDM by substituting the FDM extruder with a piston-type extruder (Figure 1a). The extrusion apparatus was designed to support many commercial syringes, ranging from 10 to $100 \mathrm{~mL}$ capacity. A $20 \mathrm{~mL}$ syringe, with a nozzle diameter of $2.25 \mathrm{~mm}$, was equipped to the system to print the specimens for compression tests. Samples with hollow cylindric shape $(15 \mathrm{~mm}$ external diameter, $10.5 \mathrm{~mm}$ internal diameter, $28 \mathrm{~mm}$ height) were printed on a metallic support; six specimens were obtained for each batch. Printings were conducted in spiral mode, a printing mode that converts the subsequent layers in a continuous spiral; layer height was set at $0.6 \mathrm{~mm}$ and printing speed at $20 \mathrm{~mm} / \mathrm{s}$. 


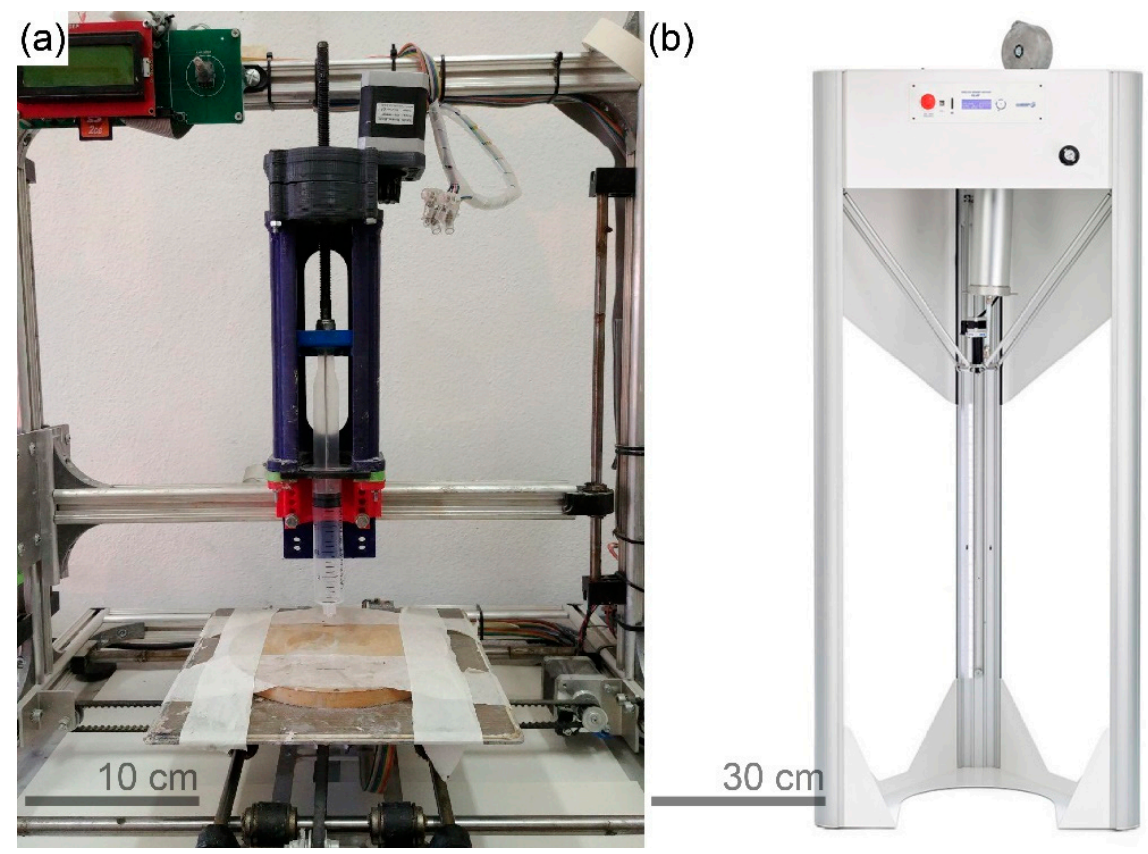

Figure 1. 3D printing setups adopted in this work: (a) 3DRag modified for LDM; (b) Delta WASP 40100 Clay.

Samples were cured at ambient temperature for 7 or 28 days, covered under a plastic sheet. After the ambient curing, some specimens were thermally treated at $800^{\circ} \mathrm{C}$ for $4 \mathrm{~h}$ in a muffle oven (model 10-D1418/ A, produced by Controls, Liscate, Italy).

The feasibility of printing structures in a scale larger than that possible with a desktop printer was assessed by a trial scale-up printing. For this purpose, a Delta WASP 40100 Clay, produced by WASP (Massa Lombarda, Italy), was used (Figure 1b). Its larger printing volume of $40 \mathrm{~cm} \times 40 \mathrm{~cm} \times$ $100 \mathrm{~cm}$, if compared with the dimension of 3DRag $(20 \mathrm{~cm} \times 20 \mathrm{~cm} \times 20 \mathrm{~cm})$, allowed larger printed structures, developed mainly in height. Unlike 3Drag, Delta WASP 40100 Clay was provided with a screw extrusion system, fed by a closed container kept under pressure, and a $4 \mathrm{~mm}$-diameter nozzle. Different printing parameters were set, as well: layer height was $2 \mathrm{~mm}$ and printing speed $85 \mathrm{~mm} / \mathrm{s}$.

\subsection{Characterization Techniques}

\subsubsection{Rheological Measurements}

Rheological characterization was carried out to understand the behavior of the pastes during the extrusion and how they were influenced by biomass. The measurements were performed by the stress-controlled rotational rheometer Kinexus Pro+ (Malvern Panalytical, Malvern, UK) equipped with the $20 \mathrm{~mm}$-diameter plate-plate geometry. The tests were carried out according to the following procedure: after a pre-shear at rate $100 \mathrm{~s}^{-1}$ for $25 \mathrm{~s}$ and a $60 \mathrm{~s}$-rest, a ramp at $125 \mathrm{~Pa} / \mathrm{s}$ was applied. The pre-shear and the consequent rest were used to normalize the starting condition of the samples. For each formulation, measurements were performed on at least three different samples; if the results were repeatable, the average stress-shear rate curve was considered for data analysis purposes.

\subsubsection{Mechanical Characterization}

Mechanical properties were assessed by compression tests done on the hardened specimens. The experiments were performed in displacement control, with the dynamometer ZwickRoell ProLine Z010 (ZwickRoell, Ulm, Germany), equipped with a $10 \mathrm{kN}$ load cell and square plates. After a preload of $5 \mathrm{~N}$, displacement was applied at constant rate of $1 \mathrm{~mm} / \mathrm{min}$ in the same direction of the printing process. The test ended when the specimen displayed a well-defined fracture pattern. For each 
specimen, compressive strength was calculated as the ratio between the maximum load sustained and the original cross-sectional area. At least five printed specimens were tested for each formulation.

\subsubsection{Microstructural and Compositional Analyses}

Microstructure morphology was investigated by scanning electron microscopy (SEM) analyses performed on geopolymer fragments belonging to fractured compression tests specimens (after 28 days of curing). The scanning electron microscope used in this work was an EVO 50 Extended Pressure, produced by ZEISS (Oberkochen, Germany). The experiments were performed in low-vacuum regime (chamber at $50 \mathrm{~Pa}$ ); the investigated surface was obtained by $\mathrm{N}_{2}$-induced brittle fracture; the electron beam was produced by a $\mathrm{LaB}_{6}$ nanocrystal source and electrons were accelerated by a potential difference of $20 \mathrm{kV}$. The experimental apparatus was equipped with a spectroscope for energy-dispersive $\mathrm{X}$-ray spectroscopy (EDS). This technique was used to perform compositional analyses in precise spots of the exposed surface.

The study of porosity was carried out by mercury intrusion porosimetry (MIP) with a MicroActive AutoPore V 9600 (Micromeritics Instrument Corp., Norcross, GA, USA). As for SEM and EDS, the analyses were made on geopolymer fragments belonging to fractured compression tests specimens.

\section{Results and Discussion}

\subsection{Printability and Buildability}

The rheological behavior of the pastes for LDM applications is of paramount importance for the quality and the structural properties of the built object. As already discussed, the most important aspects to take into account for the fresh material are printability and buildability. The former is related to the ease and the reliability of the extrusion process, while the latter refers to the ability of the fresh material to sustain the weight due to the layers deposited upon it.

These aspects can be related to the rheological properties of the material, in particular to yield stress. Perrot et al. [36] proposed a relation between buildability and the yield stress of the material deposited in the first layer, which is:

$$
H=\frac{\alpha}{\rho g} \tau_{y}
$$

where $H$ is the maximum height of the structure, $\tau_{y}$ is the yield stress, $\alpha$ is a geometrical parameter depending on the shape of the built structure, $\rho$ is the density, and $g$ is the gravity acceleration. Therefore, from this perspective, an improvement of buildability can be achieved by increasing the yield stress.

Nevertheless, since the flow begins when the yield stress is exceeded, a fluid with high yield stress may be too difficult to extrude, causing phenomena like plugging and rupture of the syringe, due the high pressure build-up. So, even though a yield stress is necessary to build a self-standing structure, it should be not higher than the maximum shear stress that the extrusion system can provide. Panda et al. [37] found an optimal range of printability for geopolymer concrete, which is in the order of $1-2 \mathrm{kPa}$ for the yield stress.

In Figure 2 the flow curves of geopolymer pastes containing different amounts of Spirulina, Tetraselmis and 5 php lignin are reported. Looking at the curves it can be noticed that the behavior of the fresh mortar is non-Newtonian (pseudo-plastic), showing yield stress, that can be found at the intercept with the ordinate axis. This kind of rheological behavior can be described by Herschel-Bulkley's model, which can be expressed by the power-law relation:

$$
\tau=\tau_{y}+K \dot{\gamma}^{n}
$$

where $\tau$ is the shear stress, $\tau_{y}$ is the yield stress, $K$ is the consistency, $\dot{\gamma}$ is the shear rate, and $n$ is the flow index. Flow curves were fitted according to Herschel-Bulkley's model to find the yield stress and the parameters $K$ and $n$. The results are shown in Table 4 . 
(a)

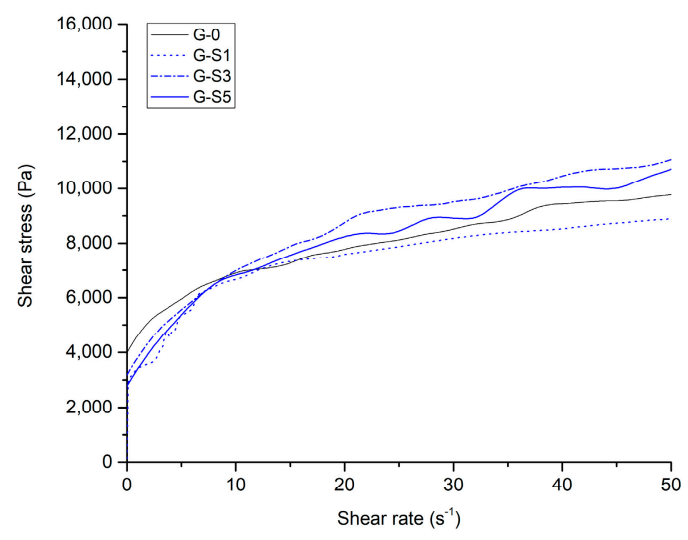

(c)

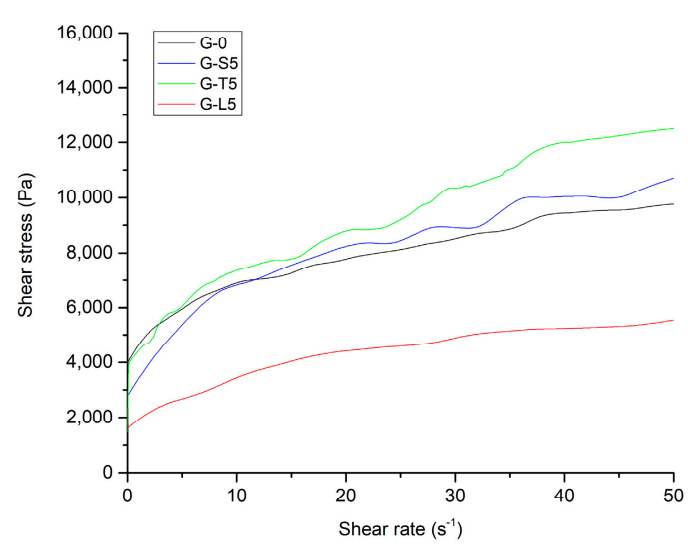

(b)

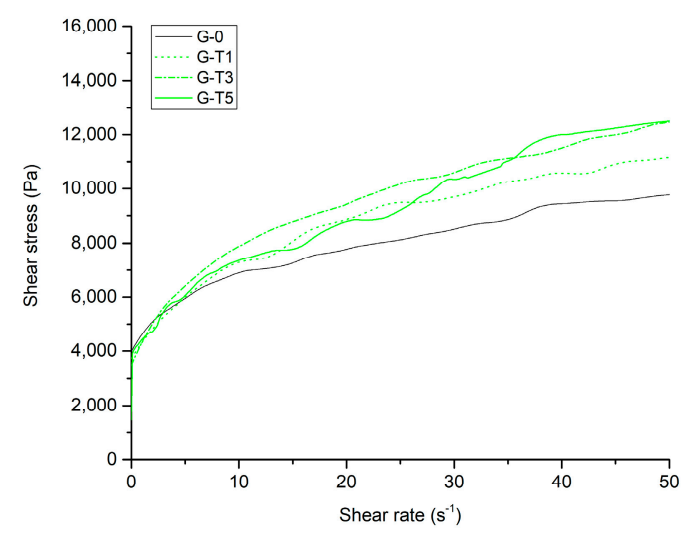

(d)

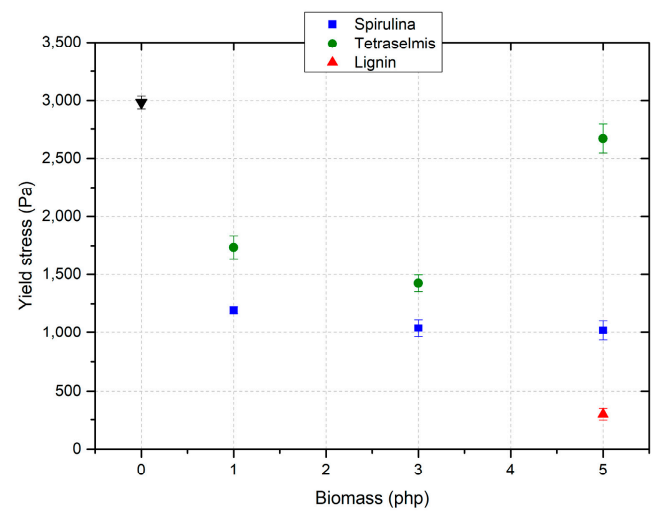

Figure 2. Results of the rheology tests performed on geopolymer pastes. (a) Flow curves of samples containing different amounts of Spirulina platensis; (b) flow curves of samples containing different amounts of Tetraselmis suecica; (c) comparison between flow curves of samples with different biomasses (Spirulina, Tetraselmis and lignin) at 5 php addition; (d) values of yield stress obtained by fitting the flow curves with Hershel-Bulkley's model.

Table 4. Herschel-Bulkley's parameters obtained from the fitting of flow curves.

\begin{tabular}{ccccc}
\hline Sample & Yield Stress $\mathbf{( P a )}$ & $\mathbf{K}\left(\mathbf{P a} \cdot \mathbf{s}^{\mathbf{n}} \mathbf{)}\right.$ & $\mathbf{n}$ & $\mathbf{R}^{\mathbf{2}}$ \\
\hline G-0 & $2984 \pm 55$ & $1717 \pm 42$ & 0.35 & 0.993 \\
G-S1 & $1195 \pm 29$ & $2479 \pm 40$ & 0.25 & 0.952 \\
G-S3 & $1040 \pm 75$ & $2847 \pm 56$ & 0.32 & 0.996 \\
G-S5 & $1022 \pm 85$ & $2605 \pm 63$ & 0.34 & 0.994 \\
G-T1 & $1737 \pm 98$ & $2658 \pm 78$ & 0.32 & 0.992 \\
G-T3 & $1424 \pm 72$ & $3034 \pm 54$ & 0.33 & 0.997 \\
G-T5 & $2670 \pm 123$ & $1733 \pm 100$ & 0.42 & 0.984 \\
G-L5 & $296 \pm 49$ & $1578 \pm 37$ & 0.31 & 0.994 \\
\hline
\end{tabular}


Fitting with Herschel-Bulkey's model was very successful $\left(R^{2}\right.$ between 0.952 and 0.997), confirming that the pastes were pseudo-plastic fluids showing yield stress. This rheological behavior is typical of solid dispersed phases organized in continuous three-dimensional structures (coagulated structures), which are broken by the application of stresses higher than a certain threshold (the yield stress). In these systems, yield stress depends on the nature, the concentration, and the interactions between the solid particles dispersed in the liquid medium [38]. In the case of this study, the dispersing medium was constituted by the alkaline activator solution and water, while the dispersed particles were metakaolin, bentonite and biomass flocs.

Biomass deeply affects the value of the yield stress, for any species and concentration investigated. The yield stress is indeed reduced in any case, because biomass flocs, which do not interact with the dispersed aluminosilicate particles, actually hinder the geopolymer gel interactions. This causes a reduction in the resistance of the coagulated structures and, as a consequence, of yield stress. As shown graphically in Figure 2d, the decrease is monotonic in the case of Spirulina, but shows a minimum for Tetraselmis; the final increase of yield stress found at $5 \mathrm{php}$ of Tetraselmis is probably due to the absorption of water by biomass, which rises the actual concentration of the system. In the case of lignin, which was tested only at $5 \mathrm{php}$, the reduction of yield stress is much more pronounced.

The decrease of the yield stress is beneficial for the printability, but it worsens buildability. Anyway, the values obtained with Spirulina and Tetraselmis are still acceptable, referring to the aforementioned findings of Panda et al. [37]. Conversely, lignin reduces too much the yield stress, therefore precluding the possibility to develop self-sustaining structures in height.

\subsection{Mechanical Properties of the Hardened Material}

The assessment of structural properties is crucial in sight of the application of these materials in the building and construction sector. Figure 3 reports the average values of compressive strength obtained by compression tests.

Regarding non-annealed samples, no noticeable difference exists between values of compressive strength at 7 and 28 days of ambient curing. This is not surprising, since geopolymers are known as fast-setting cementitious materials, so most of the mechanical properties may be already achieved after 7 days [39].

The addition of microalgae to the geopolymer slightly reduces mechanical properties both at 7 and at 28 days (Figure 3a,b). This reduction is negligible in any case when Spirulina is added, as far as the standard deviations are considered. The same consideration holds also for Tetraselmis up to 3 php; at 5 php compressive strength is reduced with respect to the reference formulation G-0 about $21 \%$ at 7 days and $35 \%$ at 28 days.

Annealing leads to a significant improvement of mechanical properties for all the samples tested. Indeed, at the selected temperature $\left(800^{\circ} \mathrm{C}\right)$, thermal treatment induces structural changes, mainly related to sintering effects, and the reaction of unreacted particles, promoting improved mechanical properties. The treatment is more efficient on samples cured at ambient temperature 7 days, instead of 28 (Figure 3c,d). One possible explanation to this result is that at 7 days the presence of still unreacted material may ease the microstructural transformations induced by the thermal treatment.

The considerations about the effect of biomass are almost the same already made for non-annealed samples: microalgae do not influence deeply the compressive strength, and they seem to be even beneficial in some cases; conversely, the effect of lignin, especially at 7 days, is detrimental.

Therefore, microalgae can be used as filler in geopolymer pastes for 3D printing, without negatively affecting mechanical properties. 
(a)

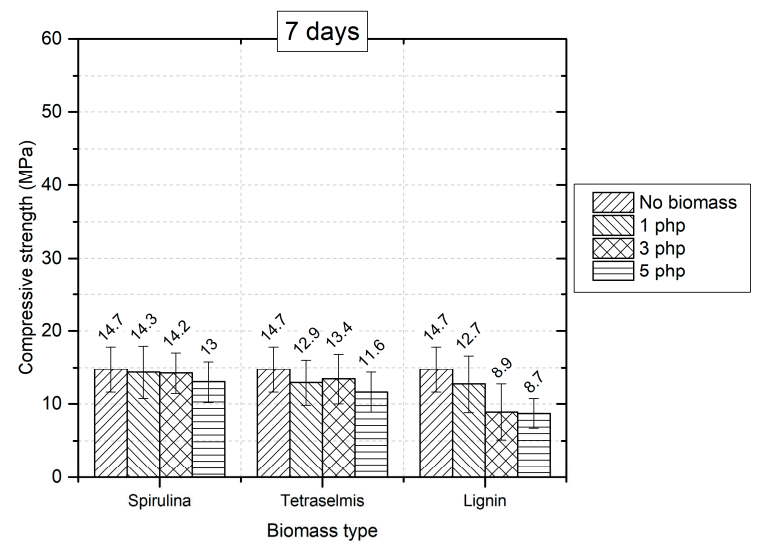

(c)

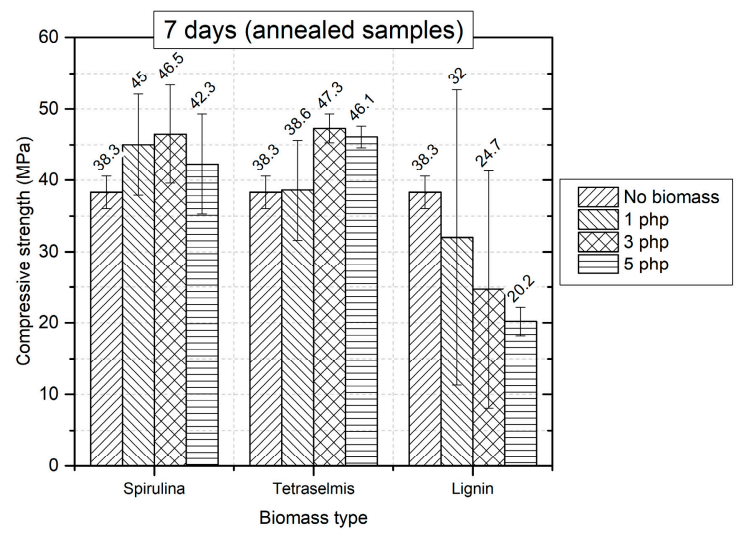

(b)

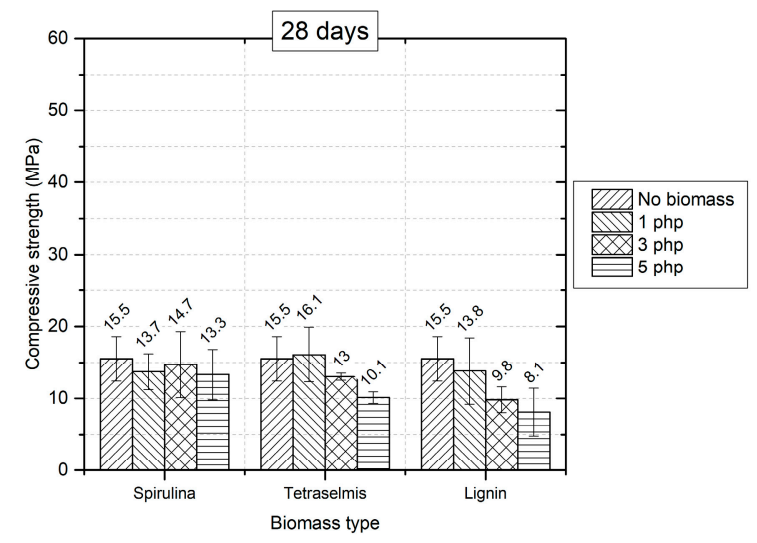

(d)

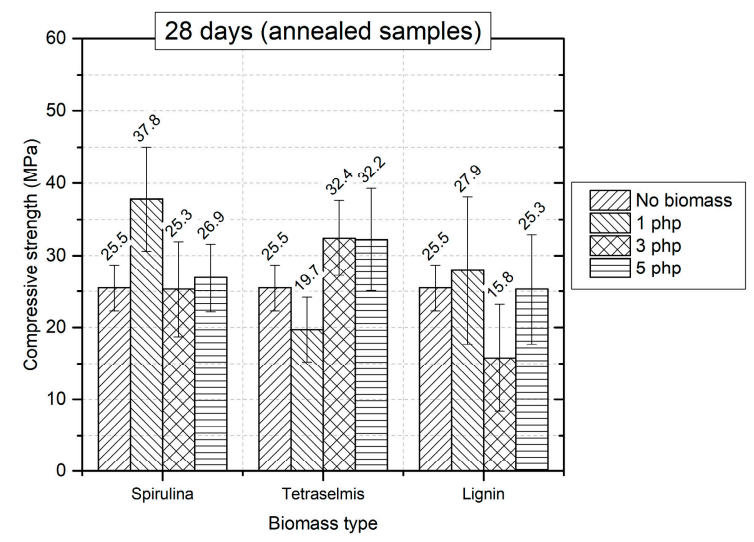

Figure 3. Mechanical properties of the hardened materials tested at different curing times and conditions: (a) after 7 days of ambient curing; (b) after 28 days of ambient curing; (c) after 7 days of ambient curing and thermal treatment; (d) after 28 days of ambient curing and thermal treatment.

\subsection{Microstructural Analyses}

Figure 4 reports the SEM micrographs, at different magnifications, of the sample G-0. In the pictures, inclusions are visible, having irregular shape surrounded by a more homogeneous matrix. Compositional analyses made by EDS showed that the matrix is mainly constituted by silicon, oxygen and aluminum-which are the constituent of the geopolymer network-while the inclusions are based on calcium that can be traced back to impurities of raw materials.

SEM micrographs of non-annealed samples containing biomass by 5 php are reported in Figure 5 . From the morphological point of view, samples containing microalgal biomass appear similar to the unfilled geopolymer. The similar structure observed, along with the similar composition verified by EDS (see Figure S1 in the Supplementary Materials), is the probable reason of the comparable values of compressive strength recorded between the unfilled material and the formulations containing microalgal biomass.

Conversely, the sample filled with lignin (Figure 5c) shows a less homogeneous microstructure, characterized by clearly visible flocculation and aggregation. The presence of these kinds of defects in the microstructure may be seen as a possible cause of the lower compressive strength of geopolymers containing lignin. 


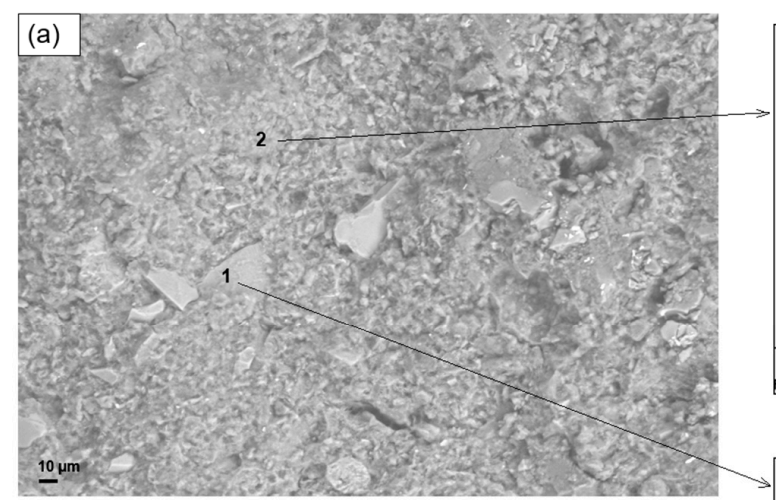

(b)

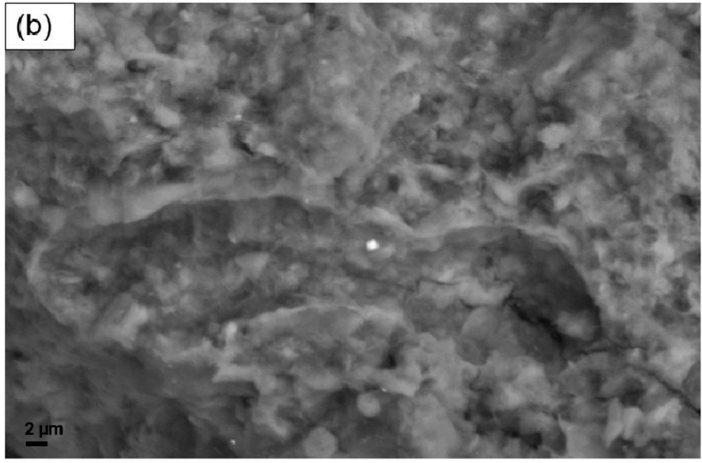

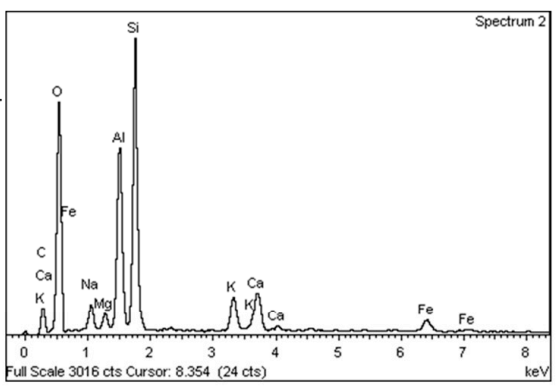

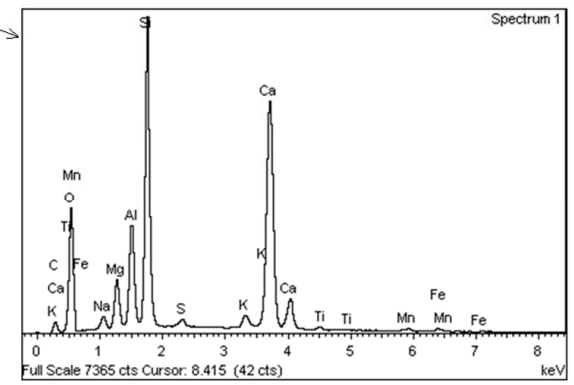

Figure 4. SEM micrographs of the reference sample G-0, at different magnifications: (a) SEM micrograph at magnification $1000 \times$ and EDS analyses on two spots (number 1 on an inclusion, number 2 on the matrix); (b) SEM micrograph at $5000 \times$ magnification.
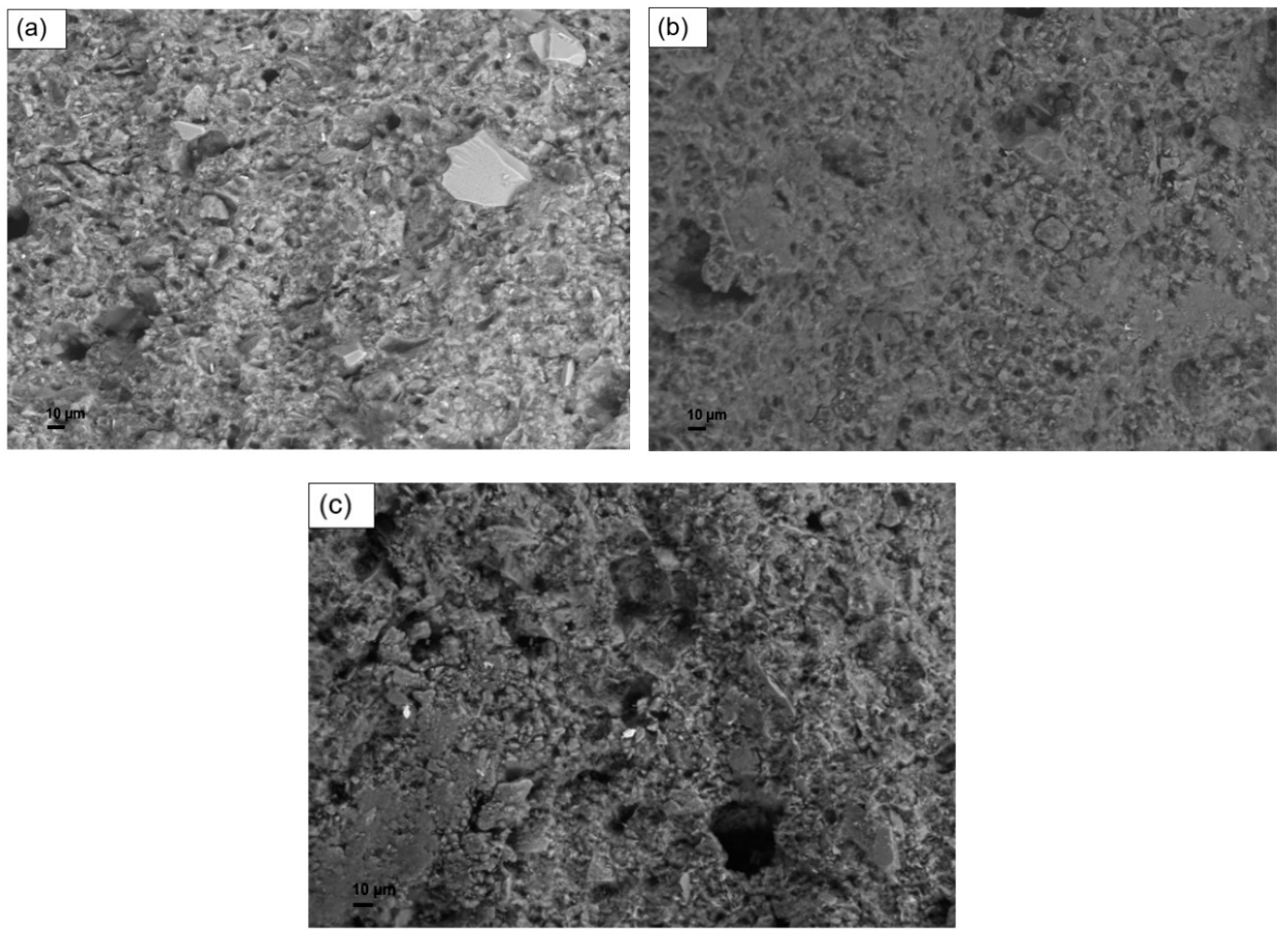

Figure 5. SEM micrographs of samples containing biomass: (a) G-S5; (b) G-T5; (c) G-L5.

Figure 6 shows the results of SEM analyses performed on the annealed samples. It can be noticed that the microstructure was profoundly modified by the thermal treatment: smoother surfaces are 
observed, which do not present flocs or agglomerates. The enhanced homogeneity of annealed samples can be related to the predicted effects of sintering between particles and promotion of the reaction of unreacted material. These beneficial effects can be related to the improved mechanical properties previously tested.
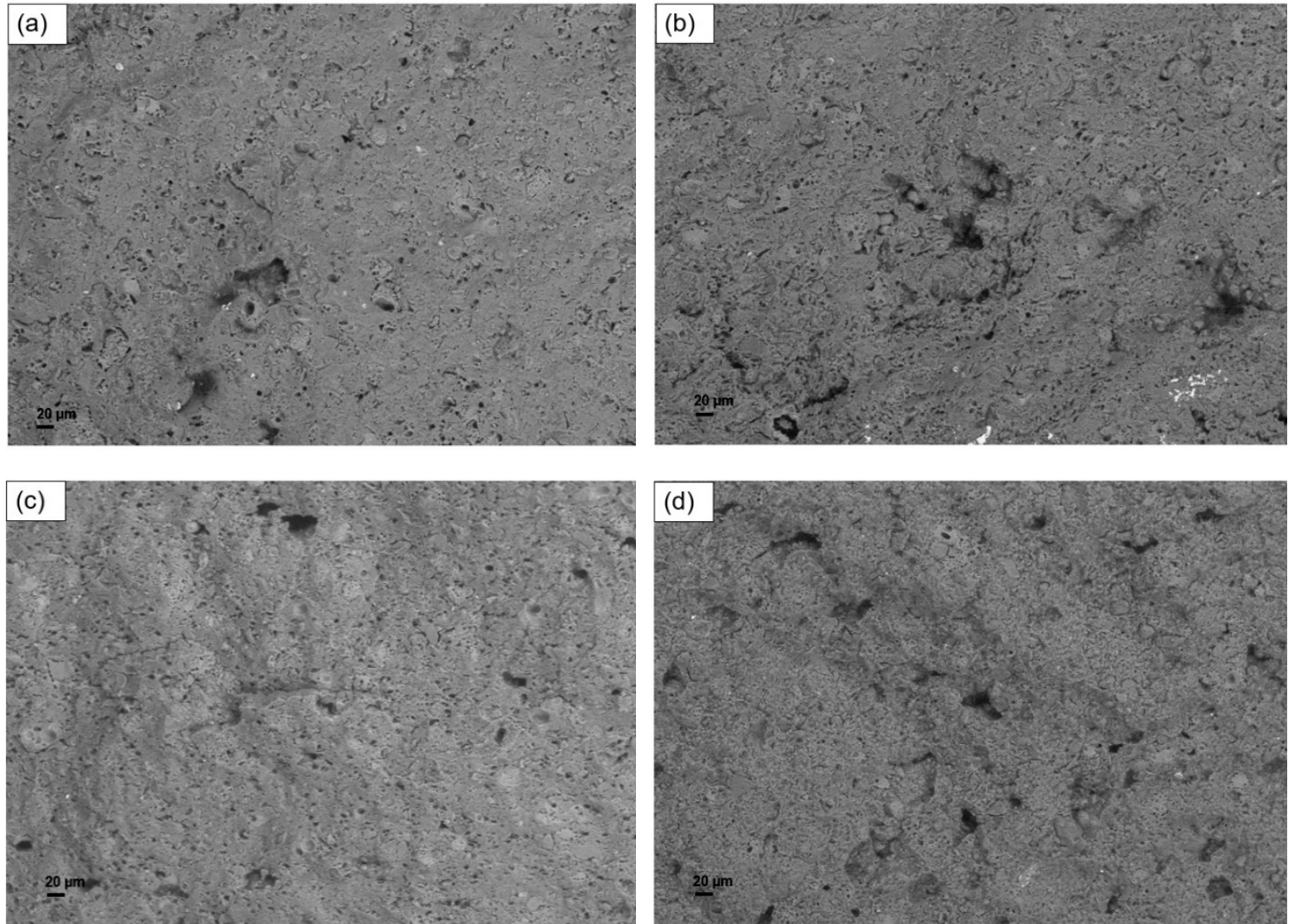

Figure 6. SEM micrographs of annealed samples: (a) G-0; (b) G-S5; (c) G-T5; (d) G-L5.

Considering porosity, Table 5 reports the results of MIP tests performed on geopolymer samples containing biomass, annealed and not. The classification of pore size is expressed considering pore radii, according to IUPAC indications [40].

Table 5. Results of MIP analyses on geopolymers containing biomass, in terms of total porosity and pore size distribution.

\begin{tabular}{|c|c|c|c|c|c|}
\hline Annealing & Sample & $\begin{array}{l}\text { Total Porosity } \\
\text { (\%) }^{1}\end{array}$ & $\begin{array}{c}\text { Mesopores } \\
(\mathrm{r}=1.25 \div \\
25 \mathrm{~nm})(\%)^{2}\end{array}$ & $\begin{array}{c}\text { Macropores } \\
(r=25 \div \\
5000 \mathrm{~nm})(\%)^{2}\end{array}$ & $\begin{array}{c}\text { Air Voids } \\
(\mathrm{r}=5000 \div \\
50,000 \mathrm{~nm})(\%)^{2}\end{array}$ \\
\hline \multirow{4}{*}{ No } & G-0 & 68.5 & 2.0 & 0.4 & 97.6 \\
\hline & G-S5 & 47.6 & 59.5 & 1.1 & 39.4 \\
\hline & G-T5 & 46.0 & 59.0 & 1.2 & 40.1 \\
\hline & G-L5 & 45.9 & 4.9 & 80.8 & 14.3 \\
\hline \multirow{4}{*}{ Yes } & G-0 & 29.5 & 0.0 & 3.3 & 96.7 \\
\hline & G-S5 & 45.8 & 4.4 & 50.0 & 45.6 \\
\hline & G-T5 & 37.1 & 13.8 & 34.8 & 51.4 \\
\hline & G-L5 & 51.3 & 4.7 & 36.1 & 59.2 \\
\hline
\end{tabular}

\footnotetext{
${ }^{1}$ Total porosity is indicated as $\%$ with respect to the whole volume. ${ }^{2}$ The values are reported as $\%$ with respect to
} the pore volume. 
Regarding the samples cured at ambient temperature, the unfilled geopolymer (G-0) shows a high amount of porosity $(68.5 \%)$, predominantly characterized by large voids (larger than $5000 \mathrm{~nm}$ ). Adding biomass, the total pore volume is reduced to values around $46-48 \%$, regardless the biomass species. In fact, biomass seems able to avoid the formation of air voids, promoting the formation of smaller pores. Specifically, Spirulina platensis and Tetraselmis suecica have almost the same effect of formation of mesopores (radius between $1.25 \mathrm{~nm}$ and $25 \mathrm{~nm}$ ), while lignin tends to promote macropores (radius between $25 \mathrm{~nm}$ and $5000 \mathrm{~nm}$ ).

MIP analyses on thermally treated samples showed that the total porosity of the unfilled geopolymer is reduced passing from $68.5 \%$ to $29.5 \%$, probably because of the already mentioned sintering process that takes place at high temperature. However, the pore size distribution remains very similar, characterized mainly by air voids. Also, in this case, biomass reduces the amount of larger voids, substituted by mesopores and macropores, even if it is no more effective in decreasing the total porosity.

The effect of biomass on porosity can be interesting for applications in which a controlled pore size distribution is required, regarding for example the production of lighter structures, inorganic foams for water filtration or components for thermal insulation.

\subsection{Large-Scale Printing Test}

The formulation with Spirulina addition by $5 \mathrm{php}$ was selected for the larger scale printing test, since it guaranteed mechanical properties comparable to the reference geopolymer formulation, it reduced yield stress improving printability and, at the same time, it maximized the amount of end-of-life material used.

Some modifications on the mixture proportions were needed to adapt to a different extrusion mechanism. In particular, to make the material flow more easily, a further reduction of yield stress was required. In order to obtain this result, bentonite amount was reduced (refer to Section 2.2 for the details). Consequently, water amount was decreased, as well.

Rheology tests performed on this formulation (U-S5) confirmed the reduction of yield stress with respect to G-S5 (Figure 7). Fitting with Herschel-Bulkley's model quantified yield stress at $595 \pm 72 \mathrm{~Pa}$ $\left(R^{2}=0.997\right)$, which is indeed much lower than that of G-S5 $(1022 \pm 85)$.

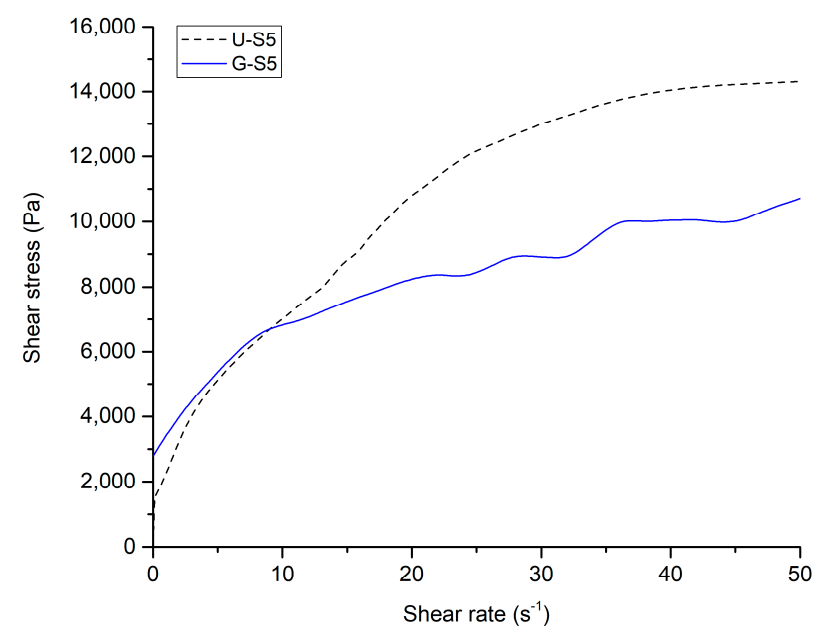

Figure 7. Comparison between the flow curves of the formulations G-S5 and U-S5.

The apparent viscosity value (i.e., the ratio between shear stress and shear rate at each point), for shear rates higher than $10 \mathrm{~s}^{-1}$, is higher for the formulation U-S5. This issue, caused by the increase of the viscosity of the dispersing medium due to the reduction of water content, was not a problem during extrusion, since the extruder geometry was optimized for highly viscous fluids. 
A hollow and self-standing, noncontinuous section structure, having a geometry very difficult to obtain with other manufacturing technologies was selected as demonstrator for the printing test. The $3 \mathrm{D}$ model is shown along with the printing process and the final result in Figure 8.
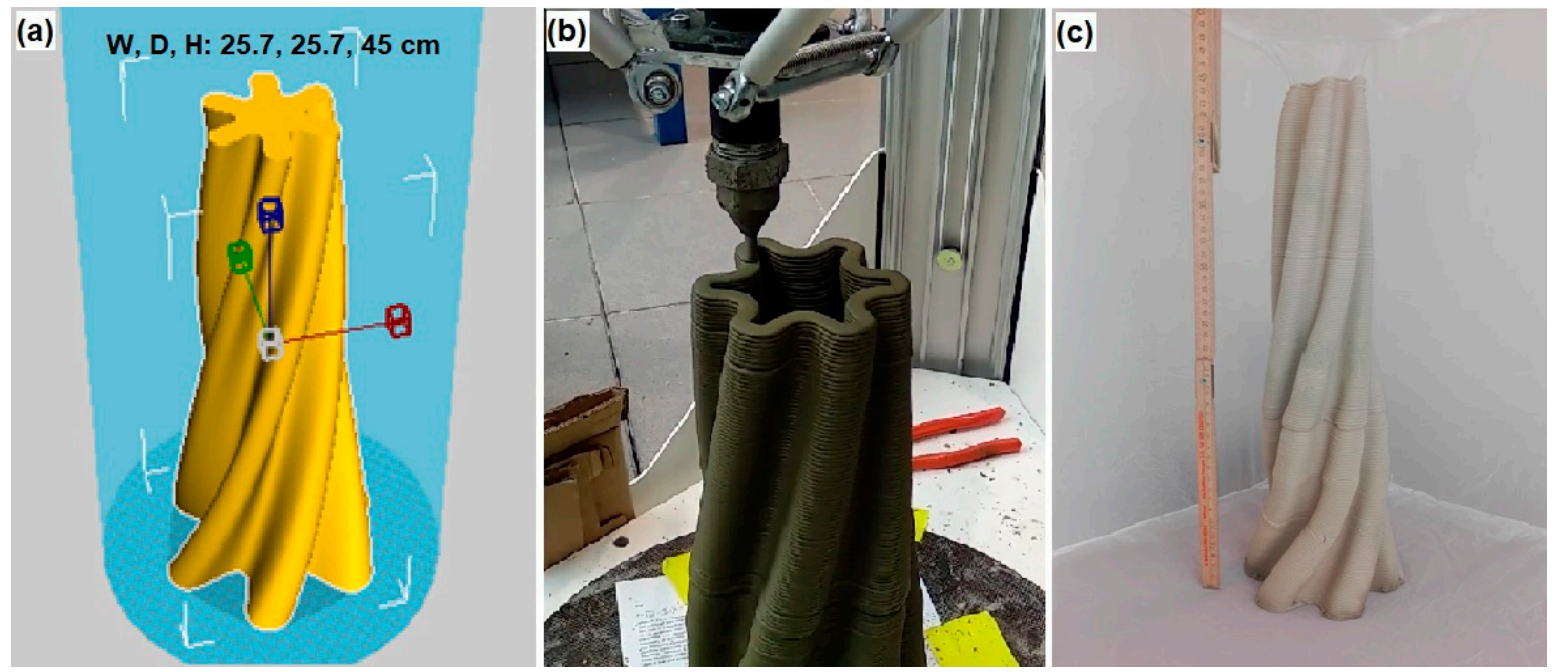

Figure 8. Scale-up process. (a) 3D model of the printed object ("W" stands for width, " $\mathrm{D}$ " depth, " $\mathrm{H}^{\prime}$ height); (b) printing process; (c) final result, after 28 days of curing at ambient temperature.

Looking at the final result, the object was successfully printed and it hardened without noticeable problems of shrinkage and cracking.

\section{Conclusions}

This paper discussed the effect of microalgal biomass on the rheological, mechanical and microstructural properties of geopolymers for the application of LDM. Various formulations containing microalgae were tested and the properties were compared with the reference geopolymer mortar and with formulations containing lignin, a different biomass which was taken as a comparison. The main results were the following:

1. Regarding rheology, the yield stress of geopolymer fresh pastes is reduced by the addition of biomass. This effect leads to a general improvement of printability in spite of buildability, which, anyway, remains acceptable in the case of microalgal biomass addition. Therefore, microalgae act as rheology modifiers for LDM-optimized geopolymer concrete.

2. Mechanical properties are only marginally affected by the addition of microalgae up to 5 php. Hence, microalgal biomasses can be used as biofiller in these construction materials.

3. Microstructure is modified by biomass addition, which affects mainly porosity. The total porosity is reduced from $68.5 \%$ to values around $46-48 \%$ by biomass addition in samples cured at ambient temperature. Moreover, biomass decreases the amount of air pores (i.e., pores larger than $5000 \mathrm{~nm}$ ), promoting smaller pore conformations in geopolymer materials, such as macropores and mesopores.

4. Annealing, performed at $800{ }^{\circ} \mathrm{C}$ for $4 \mathrm{~h}$, improved mechanical properties, by promoting sintering and the reaction of unreacted material.

5. The feasibility of obtaining large size objects was demonstrated by the successful 3D printing of a 45-cm-tall structure.

For the first time in literature, this study demonstrated the possibility of incorporating microalgal biomass wastes into metakaolin-based geopolymer cement paste for additive manufacturing applications, paving the way for a more sustainable disposal of these end-of-life materials. 
Further developments of this work are needed to study other important aspects, such as setting time of the cementitious pastes and the long-term durability and weathering resistance of the hardened material, which are of paramount importance when dealing with cementitious materials.

Supplementary Materials: The following are available online at http:/ /www.mdpi.com/1996-1944/12/7/1004/ s1, Figure S1: EDS analyses performed on samples containing biomass: (a) G-S5; (b) G-T5; (c) G-L5.

Author Contributions: Conceptualization, M.L., S.T.; methodology, M.L., S.T.; validation, E.A., R.C.; formal analysis, E.A.; investigation, E.A., R.C.; resources, E.A., R.C.; data curation, E.A., R.C.; writing-original draft preparation, E.A.; writing-review and editing, E.A., R.C., M.L., S.T.; visualization, E.A.; supervision, M.L., S.T.; project administration, M.L., S.T.; funding acquisition, M.L., S.T.

Funding: SaltGae project has received funding from the European Union's Horizon 2020 research and innovation program under Grant Agreement No 689785.

Acknowledgments: The authors would like to acknowledge Archimede Ricerche for the microalgal biomass supply, and Extractis for the chemical analyses performed.

Conflicts of Interest: The authors declare no conflicts of interest.

\section{References}

1. Berman, B. 3-D printing: The new industrial revolution. Bus. Horiz. 2012, 55, 155-162. [CrossRef]

2. Gibson, I.; Rosen, D.; Stucker, B. Additive Manufacturing Technologies: 3D Printing, Rapid Prototyping, and Direct Digital Manufacturing; Springer: New York, NY, USA, 2015; ISBN 978-1-4939-2112-6.

3. Campbell, T.; Williams, C.; Ivanova, O.; Garrett, B. Could 3D Printing Change the World? Technologies, Potential, and Implications of Additive Manufacturing. Atlantic Council Strategic Foresight Report. 2011. Available online: http:/ / www.cbpp.uaa.alaska.edu/afef/Additive\%20MFG\%20.pdf (accessed on 15 March 2019).

4. Ngo, T.D.; Kashani, A.; Imbalzano, G.; Nguyen, K.T.Q.; Hui, D. Additive manufacturing (3D printing): A review of materials, methods, applications and challenges. Composites Part B 2018, 143, 172-196. [CrossRef]

5. Wolfs, R.J.M.; Bos, F.P.; Salet, T.A.M. Early age mechanical behaviour of 3D printed concrete: Numerical modelling and experimental testing. Cem. Concr. Res. 2018, 106, 103-116. [CrossRef]

6. Ma, G.W.; Wang, L.; Ju, Y. State-of-the-art of 3D printing technology of cementitious material-An emerging technique for construction. Sci. Chin. Technol. Sci. 2017, 1-21. [CrossRef]

7. Wu, P.; Wang, J.; Wang, X. A critical review of the use of 3-D printing in the construction industry. Autom. Constr. 2016, 68, 21-31. [CrossRef]

8. Cesaretti, G.; Dini, E.; De Kestelier, X.; Colla, V.; Pambaguian, L. Building components for an outpost on the Lunar soil by means of a novel 3D printing technology. Acta Astronaut. 2014, 93, 430-450. [CrossRef]

9. Canessa, E.; Fonda, C.; Zennaro, M. Low-Cost 3D Printing for Science, Education E Sustainable Development; ICTP: Trieste, Italy, 2013; ISBN 9295003489.

10. Khoshnevis, B.; Dutton, R. Innovative Rapid Prototyping Process Makes Large Sized, Smooth Surfaced Complex Shapes in a Wide Variety of Materials. Mater. Technol. 1998, 13, 53-56. [CrossRef]

11. Khoshnevis, B.; Hwang, D.; Yao, K.-T.; Yeh, Z. Mega-scale fabrication by contour crafting. Int. J. Ind. Syst. Eng. 2006, 1, 301-320. [CrossRef]

12. Invernizzi, M.; Natale, G.; Levi, M.; Turri, S.; Griffini, G. UV-assisted 3D printing of glass and carbon fiber-reinforced dual-cure polymer composites. Materials 2016, 9, 583. [CrossRef]

13. Postiglione, G.; Natale, G.; Griffini, G.; Levi, M.; Turri, S. Conductive 3D microstructures by direct 3D printing of polymer/carbon nanotube nanocomposites via liquid deposition modeling. Composites Part $A$ 2015, 76, 110-114. [CrossRef]

14. Lim, S.; Buswell, R.A.; Le, T.T.; Austin, S.A.; Gibb, A.G.F.; Thorpe, T. Developments in construction-scale additive manufacturing processes. Autom. Constr. 2012, 21, 262-268. [CrossRef]

15. Nematollahi, B.; Vijay, P.; Sanjayan, J.; Nazari, A.; Xia, M.; Naidu Nerella, V.; Mechtcherine, V. Effect of Polypropylene Fibre Addition on Properties of Geopolymers Made by 3D Printing for Digital Construction. Materials 2018, 11, 2352. [CrossRef]

16. Nazari, A.; Sanjayan, J.G. Handbook of Low Carbon Concrete; Elsevier: Oxford, UK, 2017; ISBN 9780128045404.

17. Damineli, B.L.; Kemeid, F.M.; Aguiar, P.S.; John, V.M. Measuring the eco-efficiency of cement use. Cem. Concr. Compos. 2010, 32, 555-562. [CrossRef] 
18. Komnitsas, K.A. Potential of geopolymer technology towards green buildings and sustainable cities. Procedia Eng. 2011, 21, 1023-1032. [CrossRef]

19. Meyer, C. The greening of the concrete industry. Cem. Concr. Compos. 2009, 31, 601-605. [CrossRef]

20. Duxson, P.; Provis, J.L.; Lukey, G.C.; van Deventer, J.S.J. The role of inorganic polymer technology in the development of "green concrete". Cem. Concr. Res. 2007, 37, 1590-1597. [CrossRef]

21. Ferone, C.; Colangelo, F.; Cioffi, R.; Montagnaro, F.; Santoro, L. Mechanical performances of weathered coal fly ash based geopolymer bricks. Procedia Eng. 2011, 21, 745-752. [CrossRef]

22. Ferone, C.; Colangelo, F.; Roviello, G.; Asprone, D.; Menna, C.; Balsamo, A.; Prota, A.; Cioffi, R.; Manfredi, G. Application-Oriented Chemical Optimization of a Metakaolin Based Geopolymer. Materials 2013, 6, 1920-1939. [CrossRef]

23. Habert, G.; Ouellet-Plamondon, C. Recent update on the environmental impact of geopolymers. RILEM Tech. Lett. 2016, 1, 17. [CrossRef]

24. Duxson, P.; Fernández-Jiménez, A.; Provis, J.L.; Lukey, G.C.; Palomo, A.; Van Deventer, J.S.J. Geopolymer technology: The current state of the art. J. Mater. Sci. 2007, 42, 2917-2933. [CrossRef]

25. Provis, J.L.; van Deventer, J.S.J. Geopolymers; CRC Press: Boca Raton, FL, USA, 2009; ISBN 9781845692636.

26. Zuhua, Z.; Xiao, Y.; Huajun, Z.; Yue, C. Role of water in the synthesis of calcined kaolin-based geopolymer. Appl. Clay Sci. 2009, 43, 218-223. [CrossRef]

27. Davidovits, J. Geopolymers: Ceramic-like inorganic polymers. J. Ceram. Sci. Technol. 2017, 8, 335-350.

28. Duxson, P.; Provis, J.L.; Lukey, G.C.; Mallicoat, S.W.; Kriven, W.M.; Van Deventer, J.S.J. Understanding the relationship between geopolymer composition, microstructure and mechanical properties. Colloids Surfaces A Physicochem. Eng. Asp. 2005, 269, 47-58. [CrossRef]

29. Liew, Y.M.; Heah, C.Y.; Mohd Mustafa, A.B.; Kamarudin, H. Structure and properties of clay-based geopolymer cements: A review. Prog. Mater. Sci. 2016, 83, 595-629. [CrossRef]

30. Sudagar, A.; Andrejkovičová, S.; Patinha, C.; Velosa, A.; McAdam, A.; da Silva, E.F.; Rocha, F. A novel study on the influence of cork waste residue on metakaolin-zeolite based geopolymers. Appl. Clay Sci. 2018, 152, 196-210. [CrossRef]

31. Shayan, A.; Xu, A. Value-added utilisation of waste glass in concrete. Cem. Concr. Res. 2004, 34, 81-89. [CrossRef]

32. Abdel-Raouf, N.; Al-Homaidan, A.A.; Ibraheem, I.B.M. Microalgae and wastewater treatment. Saudi J. Biol. Sci. 2012, 19, 257-275. [CrossRef] [PubMed]

33. Abdulsada, Z.K. Evaluation of Microalgae for Secondary and Tertiary Wastewater Treatment. Ph.D. Thesis, Carleton University, Ottawa, ON, Canada, December 2014.

34. Ruiz, J.; Álvarez, P.; Arbib, Z.; Garrido, C.; Barragán, J.; Perales, J.A. Effect of nitrogen and phosphorus concentration on their removal kinetic in treated urban wastewater by Chlorella vulgaris. Int. J. Phytorem. 2011, 13, 884-896. [CrossRef] [PubMed]

35. SaltGae Project Overview. Available online: http://www.saltgae.eu (accessed on 2 February 2019).

36. Perrot, A.; Rangeard, D.; Pierre, A. Structural built-up of cement-based materials used for 3D-printing extrusion techniques. Mater. Struct. Constr. 2016, 49, 1213-1220. [CrossRef]

37. Panda, B.; Paul, S.C.; Hui, L.J.; Tay, Y.W.D.; Tan, M.J. Additive manufacturing of geopolymer for sustainable built environment. J. Clean. Prod. 2018, 167, 281-288. [CrossRef]

38. Malkin, A.Y.; Isayev, A.I. Rheology Concepts, Methods, and Applications, 3rd ed.; ChemTec Publishing: Toronto, ON, Canada, 2012; ISBN 978-0-12-525440-3.

39. Komnitsas, K.; Zaharaki, D. Geopolymerisation: A review and prospects for the minerals industry. Miner. Eng. 2007, 20, 1261-1277. [CrossRef]

40. Kong, D.L.Y.; Sanjayan, J.G.; Sagoe-Crentsil, K. Comparative performance of geopolymers made with metakaolin and fly ash after exposure to elevated temperatures. Cem. Concr. Res. 2007, 37, 1583-1589. [CrossRef]

(C) 2019 by the authors. Licensee MDPI, Basel, Switzerland. This article is an open access article distributed under the terms and conditions of the Creative Commons Attribution (CC BY) license (http:/ / creativecommons.org/licenses/by/4.0/). 